\title{
Internal particulate matter pollution in educational building
}

\author{
Nowak-Dzieszko K..$^{*}$, Kisilewicz T. \\ Cracow University of Technology
}

\begin{abstract}
The authors undertook research on the proper strategy of operation of educational building with gravitational ventilation in historic city center with high concentration of particulate matter PM10 and PM 2.5. In this facility the momentary increase in carbon dioxide concentration is often very high, and at the same time health requirements regarding atmospheric aerosol should be absolutely met. That is why long-term measurements of PM concentration outside and inside, as well as carbon dioxide concentration inside were carried out. $\mathrm{CO}_{2}$ was used also as a tracer gas for measurement of air change intensity. The article presents the first results of these tests and a correlation that occurs between the external and internal concentration of particulate matter PM 10 and PM 2.5. Due to a significant filtration effect of the external building envelope and particle deposition a potential conflict between required gravitational ventilation intensity and internal air pollution with particulate matters was partially reduced.
\end{abstract}

\section{Introduction}

Two things work against Krakow's air quality: pollution and geographical factors that prevent the dispersal of pollution. Krakow, a city of great historical value and the former capital of Poland, is located in a very large valley. This unfavourable location makes natural ventilation of the city very difficult and for many days of the year the air speed is very low here. Due to the wide use of coal for apartment heating and intense urban traffic in the historic city centre, emission of pollutants is high, which causes a high concentration of atmospheric particulate matter PM10 and PM2.5. Effective ventilation of building interior is to maintain good indoor air quality by, among others, limiting the concentration of carbon dioxide, air humidity, chemical pollution, etc. At the same time, during periods of very high atmospheric PM concentration, the intended air exchange should be significantly reduced. The authors undertook research on the proper strategy of operation of buildings with gravitational ventilation in these conditions, and in particular educational buildings. In these facilities, in densely occupied spaces, the momentary increase in carbon dioxide concentration is often very high, and at the same time health requirements regarding atmospheric pollutions should be absolutely met. The mechanisms of diffusion of suspended particles in the atmosphere into the building are not yet recognized, as well as the relationship between particles concentration and ventilation or air infiltration. That is why long-term measurements of PM concentration outside and inside, as well as carbon dioxide concentration inside are carried out in the educational building. In addition, the infiltration tightness of the monitored room was tested by means of the pressure method and random air exchange measurements by means of the trace gas method are conducted. The article presents the first results of these tests and the correlations between the concentration of particulate matter PM 10 and PM2.5 in the interior and surroundings of the building, and the concentration of carbon dioxide. The purpose of the research is to indicate the rules of space use that will limit users' exposure to adverse conditions.

\section{Indoor air quality factors}

\subsection{Building ventilation}

Building ventilation system provides the fresh and removes contaminated and humid air to and from the interior environment which is crucial for the internal air quality. Indoor air quality is significantly associated with ventilation. Low ventilation air exchange can negatively affect the inside air quality and people's health. On the other hand the same process of air exchange supplies the external contaminated air to the internal environment. Intentional air exchange in form of ventilation should be considered in conjunction with infiltration (uncontrolled and unintentional airflows) through the leaks in the building envelope.

The efficiency of air exchange can be evaluated using gas tracing method. One of the gases which may be used as a medium in those measurements is carbon dioxide. The $\mathrm{CO}_{2}$ generated by users can be treated as the tracer gas. It makes the tests simpler and cheaper as no artificial gas emitters are required. Gas tracing measurement with $\mathrm{CO}_{2}$ allows for simultaneous evaluation of ventilation efficiency, building airtightness and also partially air quality. This approach to the problem was suggested by

\footnotetext{
* Corresponding author: knowak-dzieszko@pk.edu.pl
} 
Persily [1], who presented some techniques to evaluate the building ventilation efficiency and indoor air quality analyzing carbon dioxide concentration within the internal space. The similar problems were described by Bulinska [2], who used metabolically generated carbon dioxide to determine efficiency of ventilation systems in the buildings. Zhang [3], Nowak-Dzieszko [4] used the same method while testing the ventilation rates of dormitories and offices. Air quality measurements in the university facilities were described by Benedettelli [5] and Cichowicz [6]. The measurements were conducted using gas tracer concentration decay method. The methodology of measurements is described in the ISO standard PN-EN12569 [7]. This method was also described by Sherman [8]. It is based on the analysis of natural decay of concentration of a tracer gas mixed with the internal air.

\section{2. $\mathrm{CO}_{2}$ concentration}

Polish legal acts do not specify admissible concentrations of carbon dioxide in atmospheric air and in rooms intended for permanent residence, for example for dwellings. Because of that, the standards and recommendations of other European countries and the United States (ANSI/ASHRAE) [9], [10] are most commonly used to determine acceptable concentrations. According to those requirements [9] the upper level of carbon dioxide concentration in spaces for permanent residence of people should not exceed $1000 \mathrm{ppm}$. To keep this requirement about $27 \mathrm{~m}^{3 /} \mathrm{h}$ of fresh air per person should be supplied per hour [9].

In every enclosed space where a human resides, the concentration of carbon dioxide increases because of depletion of the oxygen due to process of breathing. The carbon dioxide concentration in exhaled air is about $40000 \mathrm{ppm}$ [10]. However, the exact amount of $\mathrm{CO}_{2}$ produced by human body may differ depending on its weight and level of metabolic activity [9],[10].

The $\mathrm{CO}_{2}$ exhaled stream is related to the amount of oxygen consumed. The amount of oxygen consumed by one person in $\mathrm{m}^{3} / \mathrm{h}$ can be determined from the equation (1) [7]:

$$
V_{O 2}=3.6 \frac{0.0027 * A_{D} * M}{0.23 R_{q}+0.7}
$$

where: $A_{D}$ is DuBois surface (surface of human body) measured in $\mathrm{m}^{2}, \mathrm{M}$ is a metabolic rate, met ( 1 met is equal to $\left.58.2 \mathrm{~W} / \mathrm{m}^{2}\right), \mathrm{R}_{\mathrm{q}}$ is a respiratory quotient which can be assumed depending on the intensity of performed activity. The DuBois surface area can be taken as $1.8 \mathrm{~m}^{2}$ for an average adult person.

Polish regulations define the permissible concentrations and intensities of harmful factors in the working environment [11]:

1. Permissible exposure limit (NDS) - the weighted mean value of concentration, the impact on an employee of 8 hours per day and the average weekly working time during his/her working activity should not result in negative changes in his/her health and health of his/her future generations;

2. Short term permissible exposure limit (NDSCh) - mean value of concentration which should not cause negative changes in the worker's health if it is present in the work environment for not more than 15 minutes and not more than 2 times during the work shift, with the a time interval not shorter than 1 hour.

3. Maximum exposure limit (NDSP) - value of concentration which due to health or life threat of the worker, cannot be exceeded in the work environment at any time.

According to this regulation NDS of carbon dioxide is $5000 \mathrm{ppm}(9000 \mathrm{mg} / \mathrm{m} 3)$, and NDSCh cannot exceed $15000 \mathrm{ppm}(27000 \mathrm{mg} / \mathrm{m} 3)$.

Permissible levels of carbon dioxide in nonresidential spaces are regulated by the standard PNEN16798-3 [12]. It introduces four acceptable levels of carbon dioxide concentration depending on the selected level of indoor air quality. The table 1 shows the permissible values of the carbon dioxide concentration according to the air quality category.

In Poland there are no formal and obligatory requirements regarding the acceptable levels of $\mathrm{CO}_{2}$ concentration in the university educational buildings. Polish designers use the guidelines of the European standard in their work, attempting to maintain $\mathrm{CO}_{2}$ concentration not higher than $1000 \mathrm{ppm}$.

Table 1. Permissible values for carbon dioxide concentration to the air quality category according to standard PN-EN 167983 [12]

\begin{tabular}{|c|c|}
\hline $\begin{array}{c}\text { Category of air } \\
\text { quality in the room }\end{array}$ & $\begin{array}{c}\text { Increment of } \mathrm{CO}_{2} \\
\text { concentration above } \mathbf{C O}_{2} \\
\text { level in external air, [ppm] }\end{array}$ \\
\hline High quality of air & 350 \\
\hline Medium quality of air & 500 \\
\hline Moderate quality of air & 800 \\
\hline Low quality of air & 1200 \\
\hline
\end{tabular}

\subsection{Atmospheric particles}

Understanding of the relationship between indoor and outdoor particles concentration is very important from the occupants' perspective, especially when the levels of particulate matters outside are very high.

In the developed countries individuals spent the majority of time indoors, being exposed to the pollution in the used spaces. Epidemiological studies consistently demonstrate adverse effects of particulate matter exposure on human health. Internationally PM2,5 is estimated to cause about $3 \%$ of all mortality from cardiopulmonary disease, about $5 \%$ of mortality from cancer of the trachea, bronchus, and lung, and around $1 \%$ of mortality from acute respiratory infections in children under 5 years Cohen (2005) [13], Taylor (2014) [14]. The above 
mentioned data makes the analysis of indoor air quality very important.

In the modern buildings with mechanical ventilation systems equipped with filters, the air entering the building through infiltration and ventilation is partially cleaned. The effects of using the filters were described by Quang (2013) [15] and Spilak (2014) [16]. The usage of HEPA filters or PFU (particle filtration units) can reduce the internal concentration of particles up to $60 \%$.

In buildings with gravitational ventilation the amount of particles transported to the inside is strictly connected with air infiltration mechanism. The correlation between indoor and outdoor particle concentration can be described by the widely used parameter (I/O ratio) indoor/outdoor ratio [17].

$$
\mathrm{I} / \mathrm{O} \text { ratio }=\mathrm{C}_{\text {in }} / \mathrm{C}_{\text {out }}
$$

Where $\mathrm{C}_{\text {in }}$ and $\mathrm{C}_{\text {out }}$ are the indoor and outdoor particle concentration, respectively.

If the external concentration of particulate matters outside does not change much within the year the building can be described with the specific I/O value. The results of multiple studies on this issue were described by Chen (2011) [17], Almeida (2011) [18]. In many countries the problem is connected with the high level of particulate matters' emission inside the buildings. In these conditions low intensity of ventilation is a problem as the contaminants can not be easily removed. In one case described in [17] I/O ratio was equal to 34. In Cracow we have the opposite relation. High level of contaminants is observed outside the building and the microparticles are transferred to the inside due to ventilation and air infiltration.

The indoor concentration of particulate matters is also affected by indoor sources, smoking and fuel burning have the highest influence on I/O ratio. Monn (1997) [19] conducted the measurements in 17 houses in Switzerland, in clean environment and estimated the $\mathrm{I} / \mathrm{O}$ ratio. In houses without any indoor sources the PM I/O ratio was lower than 0.7 and in buildings with internal sources it was higher than 1.8 .

Estakova (2010) [20] conducted similiar analysis in one flat in Kosice, Slovakia, and the conclusions were similar, concentration was the highest in the kitchen due to the internal PM sources.

The room tested in this paper is free of any iternal PM sources like smoking, open fire, cooking etc.

\section{Measurements}

\subsection{Measurement methods}

Measurements with the gas tracing method, using metabolically generated carbon dioxide, were conducted using 3 Rotronic meters CP11 (Fig.1) allowing the continuous measurements and recording of $\mathrm{CO}_{2}$ concentration, temperature and relative humidity. Measurement precision of Rotronic meter is $\pm 30 \mathrm{ppm}$.
Concentration of particulate matters was measured and recorded by means of "looko2" device with laser sensors.

A)

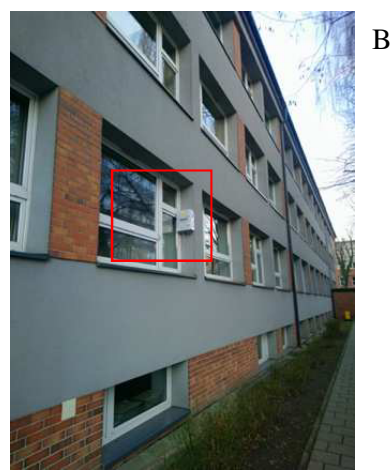

B)

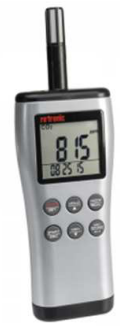

Fig. 1. A. South elevation of analysed building with PM detector located in the window area. B. Rotronic meter CP11.

The analysed room \#11 is located on the ground floor of the three-storey educational building at the main campus of Cracow University of Technology, in the old city centre. It is a computer laboratory, used by maximum 15 people. The room has only one external wall with three large $(2,55 \mathrm{~m}$ width and $1,8 \mathrm{~m}$ height) windows at south elevation of building. Fresh air is supplied in natural way by the air vents, located in PVC window frames, and exhausted by two ventilation ducts $10 \mathrm{~cm}$ by $10 \mathrm{~cm}$ located 3,0 m above floor level. There is no mechanical air handling unit and no filter system in this building. Volume of the room is $149,6 \mathrm{~m}^{3}$.

Tests were conducted between $10^{\text {th }}$ of December 2019 and $15^{\text {th }}$ of January 2020. The simultaneous measurements of $\mathrm{CO}_{2}$, PM10, PM2,5 and PM1 concentration have been conducted. Measuring devices were located on the internal wall, two meters above floor.

The same device was located outside the building on the south elevation of building to record the external PM concentration, Figure 1.

\subsection{Analysis of $\mathrm{CO}_{2}$ concentration}

Two $\mathrm{CO}_{2}$ detectors were located in two different places of the tested room in a 2 meters distance from users to avoid direct contact of the exhaled air with the sensors, according to ISO standard [7]. The concentration of carbon dioxide in a representative locations should not differ by more than $10 \%$ from the mean concentration value in the tested zone [7]. Before performing the test all the sensors were calibrated in accordance with the manufacturer's instructions.

Measurements were carried out for one month but only some representative periods were selected to emphasize the analysed phenomena. Concentration of particulate matters both inside and outside was measured continuously but only the average hourly data were recorded.

Analysis of $\mathrm{CO}_{2}$ concentration will be divided in two parts, first one while room was occupied by students and the second part when students left (analysis of $\mathrm{CO}_{2}$ concentration decay). 
Fig. 2 presents changes of $\mathrm{CO}_{2}$ concentration during one day when room was occupied by users. A sharp increase of carbon dioxide concentration can be observed when students entered the room at 12.00 , then the decline in concentration was caused by a longer break in class and next at 3:30pm. Presence of 10 people in this room resulted in the final increase of $\mathrm{CO}_{2}$ concentration up to $1400 \mathrm{ppm}$ within ca. 3 hours. Around $2.00 \mathrm{pm}$ windows were open and the concentration drop was observed. At 3:30 14 people entered the room which resulted in the increase of $\mathrm{CO}_{2}$ concentration to more than 2000 ppm within 1.5 hour.

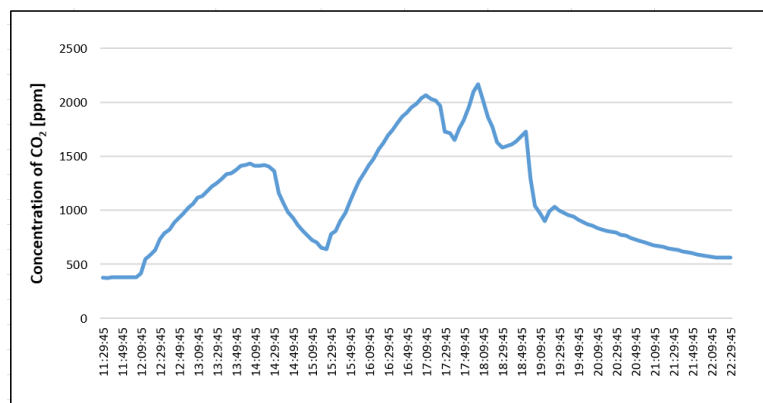

Fig. 2. $\mathrm{CO}_{2}$ concentration in the room \#11 between 11:30 am and $22: 30 \mathrm{pm}$ on January $10^{\text {th }}$.

Based on the received data the quality of internal air was classified. The external concentration of $\mathrm{CO}_{2}$ during entire measurement time was assumed at the level of $400 \mathrm{ppm}$. The internal concentration of carbon dioxide in the specific periods of time was higher than 1700. Per the classification of standard [12], that was presented in Table 1, the indoor air in tested room can be qualified as low, which is very unsatisfactory result for university educational utility.

Concetration decay data were used later to calculate the natural air flow rate by means of gas tracing method [7]. The expmple of $\mathrm{CO}_{2}$ concentartion decay curve is presented on Figure 3.

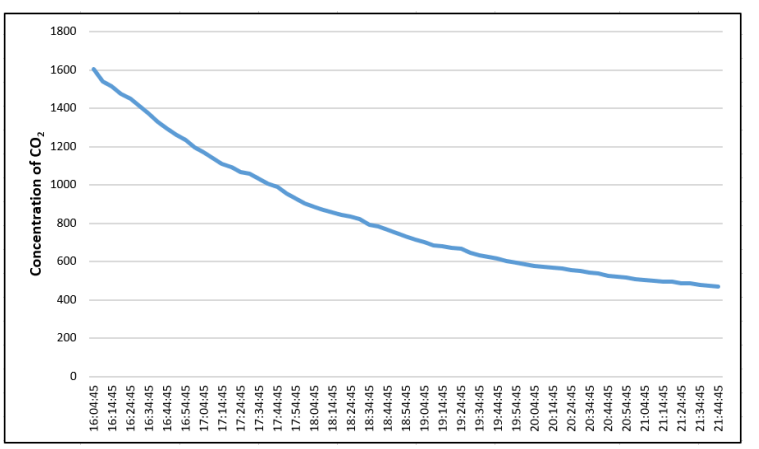

Fig. 3. $\mathrm{CO}_{2}$ concentration decay curve -02.12 .2019 .

Similar analysis and charts as above were prepared for several other selected measurement periods.

The specific airflow rates were calculated separately for five different days by means of a two point decay method. As decay period time is not strictly determined in the standard [7] different periods were analysed: one, two, and three hours from initial concentration levels. In order to calculate the air exchange rate, equation concerning 2 point decay was used.

$$
\bar{N}=\frac{1}{t_{n-1} t_{1}} \log _{a} \frac{c\left(t_{1}\right)}{c\left(t_{n}\right)}
$$

where:

$\mathrm{N}$ - time-mean specific airflow rate $(1 / \mathrm{h})$

$\mathrm{t}$ - time $\left(\mathrm{t}_{1}\right.$ : measurement start point, $\mathrm{t}_{2}$ : measurement end point) (h);

The selected results of measurements are presented in Table 2.

Table 2. Specific airflow rate calculations for different days.

\begin{tabular}{|c|c|}
\hline Date & Average $\mathrm{n}[1 / \mathrm{h}]$ \\
\hline 11.29 .2019 & 0,49 \\
\hline 30.11 .2019 & 0,51 \\
\hline 02.12 .2019 & 0,46 \\
\hline 11.01 .2020 & 0,53 \\
\hline 12.01 .2020 & 0,44 \\
\hline
\end{tabular}

The values of specific airflow rate do not differ by more than $5 \%$ between each other. The external temperature conditions were similar in the analysed periods, temperature fluctuated between $3^{\circ} \mathrm{C}$ and $6^{\circ} \mathrm{C}$.

For further considerations of the ventilation efficiency of the office room, the average airflow rate value $n=0.5[1 / \mathrm{h}]$ was assumed. This value allows for calculation of total ventilation rate equal to $75\left[\mathrm{~m}^{3} / \mathrm{h}\right]$.

Assuming 10 people working in the classroom the air flow per one person is $7.5 \mathrm{~m}^{3} /$ hour. For the maksimum of 15 users it would give only $5 \mathrm{~m}^{3} /$ hour The obtained result does not meet the requirement of a minimum 20 $\mathrm{m}^{3} / \mathrm{h}$ per person required by the standard [12].

\section{Relation between indoor and outdoor particles concentration}

As the most of people spent about $85-90 \%$ [13] of their time indoors, the understanding of relationship between indoor and outdoor particles concentration becomes very important, especially when the external pollution concentraion level outside is very high. The widely used parameter describing this relation is $\mathrm{I} / \mathrm{O}$ (indoor/outdoor) ratio which varies considerably due to the air change rates. In many countries when the topic of air quality is mainly connected with the usage of the building (internal conditions) and where the external air quality is high it is above 1. In Poland during winter months it's lower than 1 as the concentration of particulate matters outside is high. The external air quality in Poland is classified by the six Air Quality Indexes (AQI), the appropriate values of PM10 and PM2.5 concentration levels are presented in table 3. Those ranges are much higher in eastern countries and for example in China the Hazardous value of PM10 concentration is in the range $300-500$. 
Table 3. Air Quality Index in Poland (2020)

\begin{tabular}{|c|l|c|c|}
\hline & Air Quality Index & $\begin{array}{c}\mathbf{P M 1 0} \\
{\left[\boldsymbol{\mu g} / \mathbf{m}^{3}\right]}\end{array}$ & $\begin{array}{c}\mathbf{P M 2 . 5} \\
{\left[\boldsymbol{\mu g} / \mathbf{m}^{3}\right]}\end{array}$ \\
\hline $0-1$ & Good & $0-20$ & $0-13$ \\
\hline $1-3$ & Moderate & $20.1-50$ & $13.1-35$ \\
\hline $1-5$ & $\begin{array}{l}\text { Unhealthy for Sensitive } \\
\text { Groups }\end{array}$ & $50.1-80$ & $35.1-55$ \\
\hline $5-7$ & Unhealthy & $80.1-110$ & $55.1-75$ \\
\hline $7-10$. & Very unhealthy & $110.1-150$ & $75.1-110$ \\
\hline$>10$ & Hazardous & $>150$ & $>110$ \\
\hline
\end{tabular}

Figures 4 and 5 present the variations of I/O ratio and of particulate matters concentrations in period of 01.01.2020 and 05.01.2020 (hourly average data). For the lower values of PM10 concentration outside the I/O ratio is between 0,4 and 0,5. With the increase of external PM10 concentration the internal concentration levels also increase but the difference between values bocomes higher. It affects the I/O ratio which decreases to the values between 0,1 and 0,2. Even when the value of AQI outside is higher than 10 (Hazardous), internal air AQI is lower than 3 (Moderate). So there is no simple, linear relationship between these quantities. Similiar effects can be observed in the case of PM2,5 concentration, Fig. 6 and 7 .

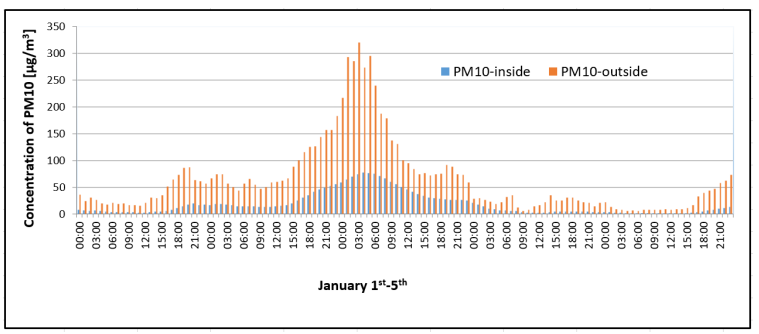

Fig. 4. Hourly data of PM10 concentration in the room 11 and external environment, $1-5^{\text {th }}$ January 2020

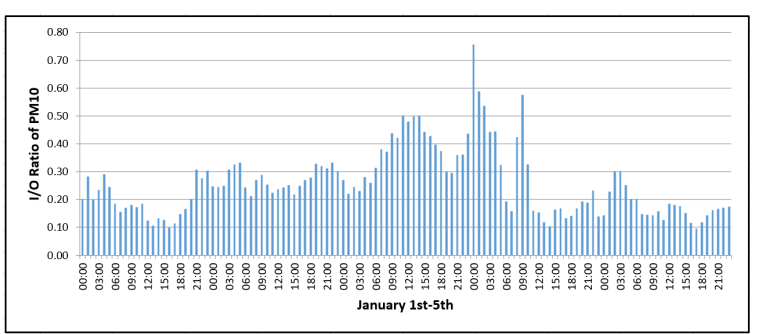

Fig. 5. Hourly values of I/O ratio of PM10, 1-5 $5^{\text {th }}$ January 2020

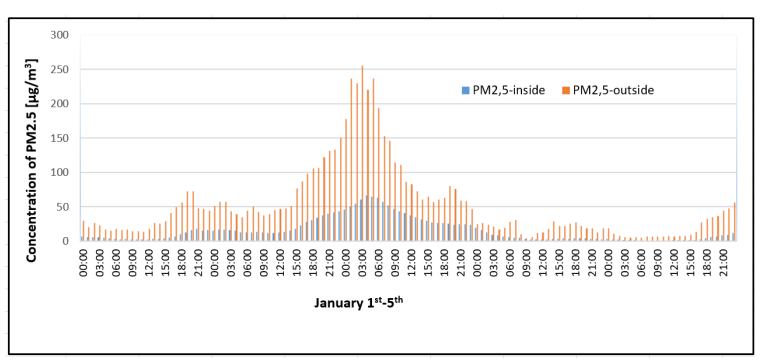

Fig. 6. Hourly data of PM2.5 concentration in the room 11 and external environment $1-5^{\text {th }}$ January 2020

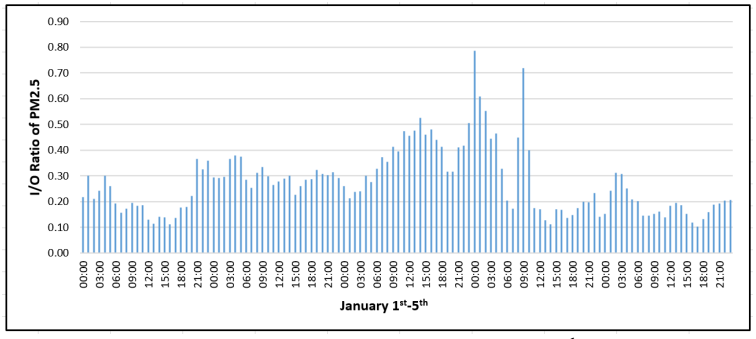

Fig. 7. Hourly values of I/O ratio of PM2.5, 1-5 ${ }^{\text {th }}$ January 2020

PM concentration in the external environment does not follow the daily cycle, according to the heating needs of city residents or vehicle traffic. The main factor determining their variability are rather atmospheric conditions: rain and wind.

Changes in PM concentration in the interior take place with a certain delay compared to the external concentration. The time lag can be estimated at about 2 hours. In the case of continuous monitoring of external conditions, this shift creates the possibility for users to respond and, for example, to avoid dangerous concetration growth.

According to a review conducted by Chen (2011) [13] linear regression can be used for simplified assessment of the infiltration factor. Fig. 8 shows a relationship between indoor air concentration of PM10 against concentration of PM10 in outdoor air of the tested room. Since there are no significant PM sources in the room, the graph practically starts at the beginning of the coordinates, the slope of the regression line corresponds to the value of the infiltration coefficient. Over $70 \%$ reduction of external PM concentration may be expected inside of tested space in average winter conditions.

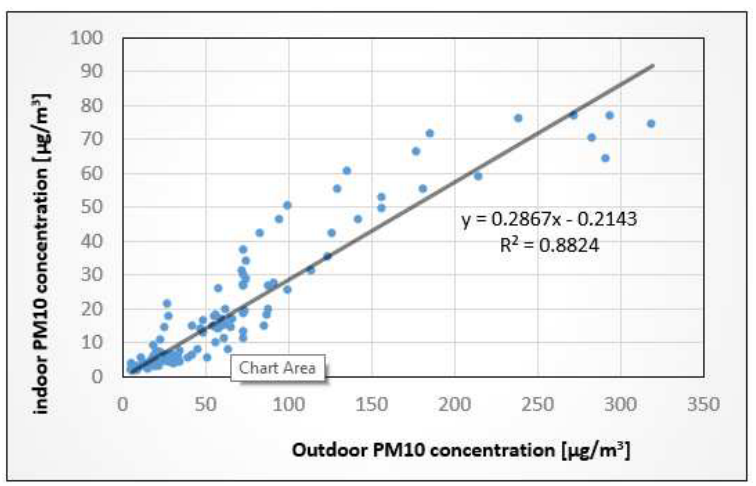

Fig. 8. Indoor vs. outdoor concentration of PM10, 1-5 $5^{\text {th }}$ January 2020

The actual value of infiltration coefficient depends in reality on the air change intensity, penetration coefficient and deposition coefficient. In buildings with natural ventilation three major deposition mechanisms may be observed: gravitational setting, Brownian diffusion and inertial impaction. These effects are, in turn, strongly dependent on the shape and size of the gaps in the building envelope, on the material characteristics of the room and its equipment and also on the size of particles suspended in the air. In case of the tested space 
infiltration coefficient is practically not sensitive to particles' size, Fig. 9.

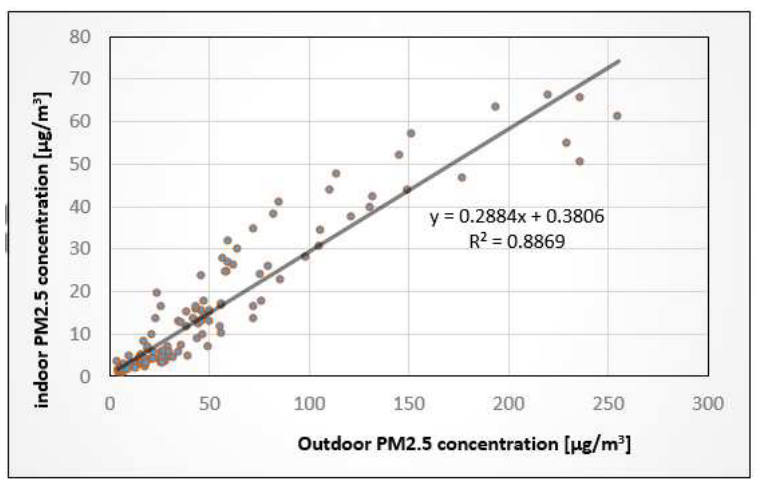

Fig. 9. Indoor vs. outdoor concentration of PM2.5, 1-5 January 2020

According to Chen (2011) [13] significant differences in the values of infiltration coefficient are observed for very fine particles (below $1 \mu \mathrm{m}$ ).

Because a particularly high concentration of PM is associated with the so-called low emission during winter, it can be stated that a massive building envelope and standard windows are efficient barrier for particulate matter transfer and prevent excessive pollution of internal air with PM particles.

\section{Conclusions}

Metabolically generated carbon dioxide, used as a tracer gas, can be a source of a unique and useful information on the space characteristics. The decay of the tracer gas allows for calculation and evaluation of ventilation system efficiency. The results of measurements can be a specific source of information about actual air change intensity.

Simultaneous measurements of particulate matters concentration inside the room and in external environment allowed to confirm that I/O (indoor/outdoor) ratio varies considerably due to the external conditions fluctuations. The high PM concentration outside the building has a decisive impact on indoor air quality, especially when there are no sources of contamination inside.

Linear regression can be used as a tool of the simplified assessment of the infiltration factor. This quantity allows an assessment of the expected indoor conditions due to external air pollution.

The conducted measurements and calculations of $\mathrm{CO}_{2}$ concentration in the classroom proved that the efficiency of ventilation system is not sufficient and the air quality is poor. In the same time the low air exchange rate may be regarded as a form of protection of the internal space against the intake of particulate matters from external environment. Filtration effect of the external building envelope and PM deposition in the room reduce a potential conflict between ventilation intensity and internal air pollution with particulate matters in building with gravitational ventilation.

\section{References}

1. Persily A. K. Evaluating Building IAQ and ventilation with indoor carbon dioxide. Ashrae transactions, 103:1-12, 1997

2. Bulińska A., Analysis of the use of metabolically generated carbon dioxide as a tracing gas for determination of indoor air exchange, Doctor Thesis, Gliwice 2011 (in Polish).

3. Zhang W., Wang L., Ji Z., Hui Y., Test on ventilation Rates of Dormitories and Offices in University by the $\mathrm{CO}_{2}$ Tracer Gas Method, Procedia Engineering 121 (2015) 662-666

4. Nowak K.; Nowak-Dzieszko K.; Marcinkowski A., Analysis of ventilation air exchange rate and indoor air quality in the office room using metabolically generated $\mathrm{CO}_{2}$, ISSN 1757-899X, 2018

5. Benedettelli M., Naticchia B., Carbonari A., Pascucci M.: Testing of Tracer Gas Based Measurement Procedure to Asses Air Change Rates in Buildings, Conference: 32nd International Symposium on Automation and Robotics in Construction, 2015

6. Cichowicz R., Gawron-Skarbek A., Godala M., Zimna-Walendzik E., Sabiniak H., Szatko F., Assesment of carbon dioxide concentration in the air of selected university facilities, Problems of Hygiene and Epidemiology 2014, 95(2): 287-291

7. ISO/FDIS 12569:2012 Thermal performance of buildings and materials - Determination of specific airflow rate in buildings - Tracer gas dilution method, 2012

8. Sherman M. H., Tracer gas techniques for measuring ventilation in a single zone, Building and Environment, Vol 25, No 4, pages 365-374, 1990.

9. ANSI/ASHRAE Standard 62.1-2019. Ventilation for acceptable indoor air quality, 2019. American Society of Heating, Refrigerating and AirConditioning Engineers

10. ASTM Standard D 6245-98. Standard guide for using indoor carbon dioxide concentrations to evaluate indoor air quality and ventilation , 1998. American Society of Heating, Refrigerating and AirConditioning Engineers

11. Regulation of the Ministry of Labor and Social Policy of November 29, 2002 regarding the highest allowable concentrations and factors harmful to health in the working environment (in Polish).

12. PN-EN 16798-3:2017, Ventilation for nonresidential buildings - Performance requirements for ventilation and room-conditioning systems, 2017.

13. Cohen A., Anderson A., ostro B., Pandey K., Krzyzanowski M., Kunzli N., Gutschmidt K., Pope A., Romieu I., Samet J., Smith K.: The global burden of desease due the outdoor air polution, Journal of Toxicology and Environmental Health, Part A, 68 : 1-7, 2005.

14. Taylor J., Shrubsole C., Davies M., Biddulph, Das P., Hamilton I., Vardoulakis S., Mavrogianni A., Jones 
B., Oikonomou E.: The modifying effect of the building envelope on population exposure to the PM2.5 from outdoor sources, Indoor Air 24 :639651, 2014.

15. Quang T., He C., Morawska L., Knibbs L., Influence of ventilation and filtration on the indoor particle concentrations in urban office buildings, Atmospheric Environment, Volume 79, p. 41-52, 2013.

16. Spilak M., Karottki G., Kolaric B., Frederiksen M., Loft S., Gunnarsen L., Evaluation of building characteristics in 27 dwellings in Denmark and the effect of using particle filtration units on PM2.5 concentrations, Building and Environment, Volume 73, p. 55-63, 2014.

17. Chen Ch., Zhao B., Review of relationship between indoor and outdoor particles : I/O ratio, infiltration factor and penetration factor, Atmospheric Environment 45 (2011) 275-288

18. Almeida S. Canha N., Silva A., Freitas M., Pegas P., Alves C., Evtyugina M., Pio C., Children exposure to atmospheric particles in indoor of Lisbon primary schools, Atmospheric Environment 45 (2011) 75947599

19. Monn Ch., Hogger D., Fuchs A., Junker M., Kogelschatz D., Roth N., Wanner H., Particulate matter less than 10um (PM10) and fine particles less than 2.5 um (PM2.5): relationships between indoor, outdoor and personal concentrations, The Science of the Total Environment 208 (1997) 15-21

20. Estakova A., Stevulova N., Kubincova L., Particulate matter investigation in indoor in indoor environment, Global NEST Journal, Vol. 12, No1 2010. 